\title{
Review
}

\section{Genetic studies on saline and sodic tolerances in soybean}

\author{
Donghe $\mathrm{Xu}^{* 1)}$ and Do Duc Tuyen ${ }^{1,2)}$ \\ 1) Japan International Research Center for Agricultural Sciences (JIRCAS), 1-1 Ohwashi, Tsukuba, Ibaraki 305-8686, Japan \\ 2) Department of Genetics and Plant Breeding, Cuulong Delta Rice Research Institute (CLRRI), Thoilai, Cantho, Vietnam
}

\begin{abstract}
Salt-affected soils are generally classified into two main categories: saline and sodic (alkaline). Developing and using soybean (Glycine max (L.) Merr) cultivars with high salt tolerance is an effective way of maintaining sustainable production in areas where soybean growth is threatened by salt stress. Early classical genetics studies revealed that saline tolerance was conditioned by a single dominant gene. Recently, a series of studies consistently revealed a major quantitative trait locus (QTL) for saline tolerance located on linkage group N (chromosome 3) around the SSR markers Satt255 and Sat_091; other minor QTLs were also reported. In the case of sodic tolerance, most studies focused on iron deficiency caused by a high soil $\mathrm{pH}$, and several QTLs associated with iron deficiency were identified. A wild soybean (Glycine soja Sieb. \& Zucc.) accession with high sodic tolerance was recently identified, and a significant QTL for sodic tolerance was detected on linkage group D2 (chromosome 17). These studies demonstrated that saline and sodic tolerances were controlled by different genes in soybean. DNA markers closely associated with these QTLs can be used for marker-assisted selection to pyramid tolerance genes in soybean for both saline and sodic stresses.
\end{abstract}

Key Words: Glycine max, Glycine soja, saline, sodic, tolerance, genetic study.

\section{Introduction}

Salt-affected soils can significantly reduce land value and productivity. Soil salt and related problems generally occur in arid or semi-arid climates, where rainfall is insufficient to leach soluble salts from the soil. Salt stress can also occur on irrigated land, particularly when irrigation water of marginal quality is used. It has been estimated that $20 \%$ of the world's irrigated land is presently affected by salt stress (Yamaguchi and Blumwald 2005). Salt-affected soils are classified into two main categories: saline and sodic (alkaline). Saline soils are generally dominated by $\mathrm{Na}^{+}$, with the dominant anions being $\mathrm{Cl}^{-}$and $\mathrm{SO}_{4}{ }^{-}$. Although the $\mathrm{pH}$ and sodium absorption ratio (SAR) values are much lower, their electrical conductivities are higher than those of sodic soils. Sodic soils are also generally dominated by the presence of excess $\mathrm{Na}^{+}$at exchange sites and a high concentration of carbonate/bicarbonate anions. They have a high $\mathrm{pH}(>8.5-10.8)$, high SAR, and poor soil structure. Table 1 demonstrates the regional distribution of salt-affected soils based on the Food and Agriculture Organization/United Nations Educational, Scientific and Cultural Organization (FAO/UNESCO) Soil Map of the World. Saline and sodic soils cover an area of 397 and

Communicated by M. Ishimoto

Received September 4, 2011. Accepted November 9, 2011.

*Corresponding author (e-mail: xudh@jircas.affrc.go.jp)
434 million ha, respectively (FAO, AGL 2000). These areas are not necessarily arable, but include all global salt-affected lands.

Saline is reported to inhibit soybean (Glycine max (L.) Merr) germination and growth (Abel and MacKenzie 1964, Wang and Shannon 1999), nodule formation (Singleton and Bohlool 1984) and seed yield (Parker et al. 1983). The average yield of 20 soybean cultivars under moderate and severe saline stress was $47.5 \%$ and $38.9 \%$ of that under no saline stress (control), respectively (Chang et al. 1994). Several studies suggest that saline-induced damage in soybean is related to the $\mathrm{Cl}^{-}$content in aerial plant parts (Abel 1969, Abel and MacKenzie 1964). Yang and Blanchar (1993) reported that the average grain yields of $\mathrm{Cl}^{-}$-accumulating cultivars were significantly decreased by $16 \%$ on addition of $\mathrm{Cl}^{-}$, while the grain yields of $\mathrm{Cl}^{-}$-excluding cultivars were not significantly decreased. Ten of 15 cultivars were identified as saline tolerant by Parker et al. (1983). They found that the average $\mathrm{Cl}^{-}$content in the leaves of susceptible cultivars was 18 times more than that found in the leaves of tolerant cultivars, and that the susceptible cultivars had 37\% lower yield than tolerant cultivars.

The most conspicuous symptom of sodic stress on plants is the induction of leaf chlorosis and stunted growth. Sodic stress has been reported to affect plant growth in many plant species, such as rice (Yang et al. 1994), wheat (Millar et al. 2007) and tomato (Biatczyk et al. 1994). Studies also 
Table 1. Regional distribution of salt-affected soils (FAO, AGL 2000)

\begin{tabular}{lcccrl}
\hline \hline Regions & $\begin{array}{c}\text { Total area } \\
\text { (million ha) }\end{array}$ & $\begin{array}{c}\text { Sodic soils } \\
\text { (million ha) }\end{array}$ & $\begin{array}{r}\text { Saline soils } \\
\text { (million ha) }\end{array}$ & \% \\
\hline Africa & 1899.1 & 33.5 & 1.8 & 38.7 & 2 \\
Asia and the Pacific & 3107.2 & 248.6 & 8 & 195.1 & 6.3 \\
and Australia & & & & & \\
Europe & 2010.8 & 72.7 & 3.6 & 6.7 & 0.3 \\
Latin America & 2038.6 & 50.9 & 2.5 & 60.5 & 3 \\
Near East & 1801.9 & 14.1 & 0.8 & 91.5 & 5.1 \\
North America & 1923.7 & 14.5 & 0.8 & 4.6 & 0.2 \\
\hline Total & 12781.3 & 434.3 & 3.4 & 397.1 & 3.1 \\
\hline
\end{tabular}

revealed that sodic stress can affect plant growth by decreasing nutrient solubility. Iron deficiency caused by high concentrations of bicarbonate ions was reported in sunflower (Alcántara et al. 1988), peanut (Zuo and Zhang 2008), maize (Celik and Vahap Katkat 2008) and soybean (Coulombe et al. 1984, Hansen et al. 2003, Norvell and Adams 2006, Zocchi et al. 2007). Rogovska et al. (2007) reported the relationship between soybean yield, soil $\mathrm{pH}$ and soil carbonate concentration and indicated that the alkalinity stress index explained $45 \%$ of the yield variability across their experimental sites.

Since the 1990s, DNA markers have been employed as a tool for identifying genes that control complex traits such as salt tolerance. In addition, DNA marker-assisted selection (MAS) has been recognized as an efficient way to accelerate the development of new, more productive and betteradapted cultivars ( $\mathrm{Xu}$ and Crouch 2008). MAS is particularly useful for breed selection and for assessing saline and sodic tolerances, which are difficult to evaluate because salt (saline and sodic) concentrations typically show either a horizontal or vertical gradient across a field. In this review, we summarize the recent advances in genetic studies, particularly those focused on quantitative trait locus (QTL) analyses of saline and sodic tolerances in soybean.

\section{Genetic studies on saline tolerance in soybean}

Classical genetic studies on saline tolerance in soybean

As mentioned above, saline soils are largely dominated by $\mathrm{NaCl}$. Most studies on Arabidopsis thaliana and rice implied that $\mathrm{Na}^{+}$is the primary lethal ion and excessive $\mathrm{Na}^{+}$accumulation is the ultimate cause of salt-induced damage (Apse et al. 1999, Quesada et al. 2002, Ren et al. 2005). In soybean, $\mathrm{Cl}^{-}$has been regarded as the major toxic element causing saline stress (Abel and MacKenzie 1964, Parker et al. 1983). They referred to saline-tolerant cultivars as $\mathrm{Cl}^{-}$ excluders and saline-sensitive cultivars as $\mathrm{Cl}^{-}$includes; however, whether $\mathrm{Na}^{+}$or $\mathrm{Cl}^{-}$plays the most critical role in $\mathrm{NaCl}$-induced mortality in soybean is still unclear.

Abel (1969) first reported the genetic control of saline tolerance in soybean. To characterize the inheritance of saline tolerance, $\mathrm{Cl}^{-}$includers (Jackson, N53-505, B54-842) were crossed with $\mathrm{Cl}^{-}$excluders (Lee, N53-509), and the parents as well as their progeny were evaluated for saline tolerance. Crosses between parents with similar $\mathrm{Cl}^{-}$accumulation capacity produced $\mathrm{F}_{2}$ and $\mathrm{F}_{3}$ progeny that were similar to their parents with respect to saline tolerance. In addition, in eight crosses between parents with different $\mathrm{Cl}^{-}$accumulation capacities, $\mathrm{F}_{2}$ plants were segregated into a $\mathrm{Cl}^{-}$excluder to includer ratio of $3: 1$. Tests of the $F_{3}$ progeny from these crosses demonstrated that the $\mathrm{F}_{2}$ excluder plants segregated into an excluder to segregating ratio of $1: 2$, whereas the $F_{2}$ includers showed no segregation. Backcrossing the $F_{1}$ plants from a cross between an includer and excluder resulted in an includer to segregating ratio of $1: 1$ when the recurrent parent was an includer and an excluder to segregating ratio of $1: 1$ when the recurrent parent was an excluder. Thus, a single dominant gene controls saline tolerance in soybean. The gene symbol $\mathrm{Ncl}$ was proposed for the dominant $\mathrm{Cl}^{-}$excluder, whereas $\mathrm{ncl}$ was proposed for the recessive $\mathrm{Cl}^{-}$includer.

Later, Shao et al. (1994) also crossed saline-tolerant and sensitive soybean varieties to study the inheritance of saline tolerance. Based on the screening of 1716 Chinese soybean germplasms and 260 American soybean germplasms in a saline field irrigated with mixture of seawater and freshwater in a ratio of $1: 1$, they identified a number of saline-tolerant varieties, such as Wen feng No. 7, Jin dou 33, Tie-feng 8, Dan dou 2, Mansoy and Morse and some saline-sensitive varieties, such as Hark and Union. The $F_{1}, F_{2}$ and $F_{3}$ progeny were tolerant when both parents were tolerant, while they were sensitive when both parents were sensitive. When a saline-tolerant variety was crossed with a sensitive variety, the $F_{1}$ plants were saline tolerant, the $F_{2}$ plants segregated into a tolerant to sensitive ratio of $3: 1$, and $F_{3}$ lines from salt-tolerant $F_{2}$ plants segregated into a homogenous tolerant to segregating ratio of $1: 2$; all the lines from sensitive $F_{2}$ plants were sensitive. Backcrossed progeny of $F_{1}$ plants with sensitive varieties as the recurrent parent had a tolerant to sensitive segregation ratio of $1: 1$. Thus, they concluded that that a single dominant nuclear gene controls saline tolerance in soybean and that saline tolerance is dominant over sensitivity. Their results were similar to those of Abel (1969), although different saline-tolerant resources were used in both studies.

In contrast to the results of Abel (1969) and Shao et al. (1994), Luo et al. (2004) reported that minor genes control soybean saline tolerance. They used $\mathrm{F}_{1}, \mathrm{~F}_{2}$, and $\mathrm{F}_{2: 3}$ lines and parental cultivars from two crosses of Nannong 88$31 \times$ Jackson and Nannong 1138-2 × Nannong 88-31. Genetic analysis revealed that saline tolerance was controlled by minor genes. The heritability value of the minor genes was estimated as $82.1 \%$ and $67.5 \%$ for the $\mathrm{F}_{2: 3}$ lines from crosses of Nannong 88-31 $\times$ Jackson and Nannong 1138-2 $\times$ Nannong 88-31, respectively. The results from these different studies may have been inconsistent because of the differences in the genetic background of parental cultivars and the evaluation method for scoring plant saline stress injury. It was not surprising that no major gene could be detected 
Table 2. Reported QTLs for saline tolerance in soybean

\begin{tabular}{|c|c|c|c|c|c|c|c|c|}
\hline \multirow{2}{*}{$\begin{array}{l}\text { Linkage } \\
\text { group }\end{array}$} & \multirow{2}{*}{$\begin{array}{l}\text { Chromo- } \\
\text { some }\end{array}$} & \multirow{2}{*}{$\begin{array}{c}\text { Neighbor } \\
\text { markers }\end{array}$} & \multirow{2}{*}{$\operatorname{PVE}(\%)^{a}$} & \multicolumn{2}{|c|}{ Parents } & \multirow{2}{*}{$\begin{array}{l}\text { Population } \\
\text { type (size) }\end{array}$} & \multirow{2}{*}{$\begin{array}{l}\text { Experiment } \\
\text { condition }\end{array}$} & \multirow{2}{*}{ Literature } \\
\hline & & & & Tolerant & Sensitive & & & \\
\hline $\mathrm{N}$ & 3 & $\begin{array}{l}\text { Sat_091, } \\
\text { Satt237 }\end{array}$ & $35-45$ & S-100 & Tokyo & $\begin{array}{l}\text { RILs } \\
(n=106)\end{array}$ & $\begin{array}{l}\text { Field and } \\
\text { greenhouse }\end{array}$ & Lee et al. (2004) \\
\hline $\mathrm{N}$ & 3 & $\begin{array}{l}\text { Satt339, } \\
\text { Satt237, } \\
\text { Satt255 }\end{array}$ & 68.7 & $\begin{array}{l}\text { JWS156-1 } \\
\text { (G. soja) }\end{array}$ & Jackson & $\begin{array}{l}\mathrm{F}_{2} \\
(n=225)\end{array}$ & Greenhouse & Hamwieh and $\mathrm{Xu}(2008)$ \\
\hline G & 18 & $\begin{array}{l}\text { Sat_164, } \\
\text { Sat_358 }\end{array}$ & 10.8 & Nannong1138-2 & Kefeng No. 1 & $\begin{array}{l}\text { RILs } \\
(n=184)\end{array}$ & $\begin{array}{l}\text { Field and } \\
\text { greenhouse }\end{array}$ & Chen et al. (2008) \\
\hline M & 7 & $\begin{array}{l}\text { Satt702, } \\
\text { Satt728 }\end{array}$ & 7.1 & Nannong1138-2 & Kefeng No. 1 & $\begin{array}{l}\text { RILs } \\
(n=184)\end{array}$ & $\begin{array}{l}\text { Field and } \\
\text { greenhouse }\end{array}$ & Chen et al. (2008) \\
\hline M & 7 & $\begin{array}{l}\text { Satt655, } \\
\text { Satt210 }\end{array}$ & 19.7 & Nannong1138-2 & Kefeng No. 1 & $\begin{array}{l}\text { RILs } \\
(n=184)\end{array}$ & $\begin{array}{l}\text { Field and } \\
\text { greenhouse }\end{array}$ & Chen et al. (2008) \\
\hline $\mathrm{N}$ & 3 & $\begin{array}{l}\text { Sat_091, } \\
\text { Sat_304 }\end{array}$ & 44.0 & FT-Abyara & $\mathrm{C} 01$ & $\begin{array}{l}\text { RILs } \\
(n=225)\end{array}$ & Greenhouse & Hamwieh et al. (2011) \\
\hline $\mathrm{N}$ & 3 & $\begin{array}{l}\text { Sat_091, } \\
\text { Sat_304 }\end{array}$ & 47.1 & Jin dou No. 6 & 0197 & $\begin{array}{l}\text { RILs } \\
(n=225)\end{array}$ & Greenhouse & Hamwieh et al. (2011) \\
\hline $\mathrm{N}$ & 3 & $\begin{array}{l}\text { Sat_091, } \\
\text { Satt339 }\end{array}$ & 31.5 & $\begin{array}{l}\text { JWS061-1 } \\
\text { (G. soja) }\end{array}$ & Jackson & $\begin{array}{l}\text { RILs } \\
(n=117)\end{array}$ & Greenhouse & $\mathrm{Xu}$ (unpublished data) \\
\hline
\end{tabular}

${ }^{a} \operatorname{PVE}(\%):$ the percentage of the phenotypic variance, which is based on the degree of saline-induced leaf chlorosis and withering, explained by the QTL

when two crossed parents contained the same allele in a major tolerance gene locus.

Wild soybean (Glycine soja Sieb. \& Zucc.) was also targeted for saline tolerance study because it can easily cross with cultivated soybean, thereby introducing its favorable genetic profile into cultivated soybean with ease. Lee et al. (2009) studied the inheritance of saline tolerance in wild soybean accession PI483463. To determine the inheritance of saline tolerance in the wild soybean accession and to test the allelism of tolerance genes from the wild soybean accession, PI483463, and a soybean cultivar, S-100, which is a common ancestor of cultivars in southern U.S. and a salinetolerant cultivar (Lee et al. 2004), saline-tolerant PI483463 was crossed with a sensitive cultivar Hutcheson and the S100 cultivar. Parent cultivars and their progenies lines were assayed in a $100 \mathrm{mM} \mathrm{NaCl}$ solution to evaluate tolerance. $\mathrm{F}_{2}$ plants from the cross of PI483463 $\times$ Hutcheson segregated into a tolerant to sensitive ratio of $3: 1$. The $\mathrm{F}_{2: 3}$ lines segregated into a tolerant to segregating to sensitive ratio of $1: 2: 1 . \mathrm{F}_{2}$ plants from the cross of PI $483463 \times \mathrm{S}-100$ segregated into a tolerant to sensitive ratio of $15: 1$, indicating different genes from the two sources. They concluded that the wild soybean accession PI483463 had a single dominant gene for saline tolerance, which differed from the gene found in the cultivated cultivar S-100. The symbol Ncl2 was proposed for this new saline tolerance allele. Unfortunately, tolerance in $\mathrm{F}_{3}$ lines from the cross of PI483463 $\times$ S-100 was not tested in this study. Further genetic studies are required to confirm whether this is a new tolerance gene.

\section{QTL analyses of saline tolerance in soybean}

A summary of QTL analyses of saline tolerance in soybean is given in Table 2. Numerous independent studies using different segregating populations, including those derived from crosses between cultivated and wild soybeans, consistently reported a major QTL on linkage group $\mathrm{N}$ (chromosome 3).

Lee et al. (2004) provided the first report of a salinetolerant QTL in soybean. They used a population of recombinant inbred lines (RILs, $n=106$ ), i.e., $\mathrm{F}_{2: 5}$ lines derived from a cross of S-100 (tolerant) $\times$ Tokyo (sensitive) cultivars, to determine the heritability of saline tolerance and to identify any associated QTL. Mapping populations were evaluated in a saline field as well as greenhouse conditions using a nutrient solution culture method. The visual salt tolerance ratings of the $\mathrm{F}_{2: 5}$ lines were scored on the basis of the degree of saline-induced leaf chlorosis and withering. Restriction fragment length polymorphism (RFLP) and simple sequence repeat (SSR) markers were employed to identify genomic regions associated with the saline-tolerant trait. A major QTL for salt tolerance was discovered near the Sat_091 SSR marker on linkage group N, accounting for $35 \%, 29 \%$ and $45 \%$ of the total genetic variation for saline tolerance in the field, greenhouse, and combined environments, respectively. Pedigree tracking was used to examine the association between the saline-tolerant QTL and flanking SSR marker alleles in U.S. cultivars that had descended from S-100 or Tokyo through 60 years of breeding. It was found that S-100 was the source of the tolerance allele in the cultivar Lee, which was used as a saline-tolerant variety in Abel's (1969) aforementioned study, suggesting that this QTL is most likely the $\mathrm{Ncl}$ gene locus.

Hamwieh et al. (2011) also performed studies to identify the QTL that conditioned saline tolerance in soybean in greenhouse experiments. Two RIL populations derived from crosses of FT-Abyara $\times$ C01 and Jin dou No. $6 \times 0197$ were 
used in their study. The FT-Abyara $\times \mathrm{C} 01$ population comprised $96 \mathrm{~F}_{7}$ RILs, whereas the Jin dou No. $6 \times 0197$ population comprised $81 \mathrm{~F}_{6}$ RILs. The salt-tolerant parents FTAbyara and Jin dou No. 6 originated from Brazil and China, respectively. QTL analysis identified a major saline-tolerant QTL in molecular linkage group $\mathrm{N}$, which accounted for $44.0 \%$ and $47.1 \%$ of the total variation of saline tolerance in the FT-Abyara $\times$ C01 and Jin dou No. $6 \times 0197$ populations, respectively. The QTL was located in the same region as that reported by Lee et al. (2004), although the tolerant resources (FT-Abyara and Jin dou No.6) used in their study have no confirmed pedigree relationship with the S-100 cultivar or any of its descendants. Thus, the same saline-tolerant QTL could be identified in different tolerant genetic resources.

Chen et al. (2008) reported different saline-tolerant QTLs in soybean. Field and greenhouse experiments were conducted to evaluate 184 RILs derived from a cross between Kefeng No. 1 (sensitive) and Nannong1138-2 (tolerant) for saline tolerance and to identify QTLs associated with saline tolerance. Eight putative QTLs significantly associated with saline tolerance traits were identified. A major QTL was identified between markers Sat_164 and Sat_358 on linkage group $\mathrm{G}$ (chromosome 18) under both field and greenhouse conditions. In addition, a minor QTL was identified on linkage group $\mathrm{N}$ at the same location as that of a previously reported saline-tolerant QTL.

Hamwieh and $\mathrm{Xu}$ (2008) performed QTL analysis of saline tolerance in wild soybean genetic resources to determine whether wild soybean possesses the same saline tolerance gene as cultivated soybean. They investigated the heredity of saline tolerance in wild soybean and compared the saline-tolerant QTL of G. soja with that of G. max. An $\mathrm{F}_{2}$ population $(n=225)$ derived from a cross between the saltsensitive soybean cultivar Jackson and the salt-tolerant wild soybean accession JWS156-1 was used. Saline tolerance was evaluated in the seedling stage in a hydroponic culture using half-strength Hoagland and Arnon nutrient solution containing $120 \mathrm{mM} \mathrm{NaCl}$. They revealed a major salt-tolerant QTL with a large dominant effect, which accounted for $68.7 \%$ of the total variance in the saline-tolerant phenotype, on soybean linkage group N. Based on the observation, they concluded that the saline-tolerant QTL confers a large dominant effect over saline sensitivity and that the saline-tolerant QTL is conserved in wild and cultivated soybeans.

We evaluated saline tolerance and performed QTL analysis using another RIL mapping population $\left(\mathrm{F}_{6}, n=117\right)$ derived from a cross between the soybean cultivar Jackson and a saline-tolerant wild soybean accession JWS061-1 in a greenhouse experiment (our unpublished data). A major salt-tolerant QTL, which accounted for $31.5 \%$ of the total variance in the saline-tolerant phenotype, was identified on soybean linkage group $\mathrm{N}$ around markers Sat_091 and Satt339. This result again supports the fact that both wild and cultivated soybeans possess a conserved saline-tolerant gene.

\section{$M A S$ of the saline-tolerant gene on linkage group $N$}

The consistent results of saline tolerance mapping among different populations or different soybean species, i.e., wild and cultivated, suggest that the QTL on linkage group $\mathrm{N}$ plays an essential role in enhancing saline tolerance against different genetic backgrounds. Lee et al. (2004) indicated that the saline-tolerant QTL detected on linkage group $\mathrm{N}$ is most likely the tolerance gene locus reported by Able (1969). They also indicated that SSR markers, such as Satt237 and Sat_091, associated with the saline-tolerant QTL could be used for MAS. Hamwieh et al. (2011) developed near-isogenic lines (NILs) for the linkage group $\mathrm{N}$ tolerant gene using MAS. Three RILs were found to be heterozygous around the QTL region detected in the FTAbyara $\times \mathrm{C} 01$ population. Three sets of NILs for saline tolerance were developed by selfing the three residual heterozygous plants. Evaluation of NIL saline tolerance revealed that all lines with an FT-Abyara chromosome segment in the QTL region demonstrated significantly higher tolerance than those without the FT-Abyara chromosome segment. The successful development and performance of saline-tolerant NILs demonstrated that the markers associated with the saline QTL were efficient for MAS of the salinetolerant gene on the QTL; however, Hamwieh et al. (2011) found that the SSR marker alleles (Satt339, Satt237, GMES1100, Satt255, Sat_091 and Sat_304) in FT-Abyara were different from those in the soybean cultivar S-100, although both cultivars were saline tolerant. Saline tolerance was not always accompanied with the SSR marker alleles in the soybean cultivar S-100 reported by Lee et al. (2004). This may be because these markers are separate from the tolerance gene, or multiple alleles or loci are responsible for saline tolerance. Development of DNA markers that are more closely associated with the tolerance gene or derived from the gene itself is required for MAS.

\section{Exploration of a new saline tolerance gene in soybean}

The fact that the saline QTL was repeatedly detected on linkage $\mathrm{N}$ caused us to consider the probability of the presence of other genes conferring saline tolerance in soybean. As mentioned above, Chen et al. (2008) detected a major QTL conferring saline tolerance on linkage group G; however, the QTL needed validation with a different genetic background. In addition, Lee et al. (2009) reported a new saline tolerance gene $(\mathrm{Ncl} 2)$ in a wild soybean accession. Wild soybean has been demonstrated as highly diverse, and some of its favorable traits have been introduced into cultivated soybean. In our laboratory, more than 1000 wild soybean germplasms from the Legume Base NBRP (http:// www.legumebase.brc.miyazaki-u.ac.jp/) and NIAS Genebank (http://www.gene.affrc.go.jp/index_j.php) have been evaluated for saline tolerance; several tolerant accessions, such as JP30932, JP30942 and JP31121, with high saline tolerance have been identified (Xu 2009). Genetic studies using progeny from crosses between these tolerant accessions and the existent tolerant as well as sensitive germplasms, such as 
S-100 (tolerant), FT-Abyara (tolerant) and Jackson (sensitive), will reveal whether these saline-tolerant wild accessions harbor any new tolerant gene. Our ongoing research project, which is focused on map-based cloning of the saline tolerance gene on linkage group $\mathrm{N}$, may provide information for studying the gene expression and structure of this gene in these new tolerant wild soybean germplasms.

\section{Genetic studies on sodic tolerance in soybean}

Iron deficiency chlorosis (IDC) in soybean caused by a high soil $p H$

Weiss (1943) first reported the genetic control of iron deficiency chlorosis (IDC) in soybean and concluded that a single recessive gene with no maternal impact affected the trait. Cianzio and Fehr (1980) evaluated IDC in a field of calcareous soils and reported that a major gene together with modifying genes controlled chlorosis. Later, the authors used a different soybean population and concluded that IDC was quantitatively controlled via additive gene action, inferring that the inheritance of the trait depends on the parents used (Cianzio and Fehr 1982).

Lin et al. (1997) conducted a study to map the genes controlling IDC in two populations. Chlorosis symptoms were evaluated in the field by visual scoring and spectrometric chlorophyll determinations. A total of 89 RFLP and 10 SSR markers for the Pride B216 $\times$ A15 population and 82 RFLP, 14 SSR and one morphological I (hilum color) marker for the Anoka $\times$ A7 population were used to map the QTL affecting IDC. QTLs having minor effects were detected on six linkage groups of the Pride B216 $\times$ A15 population, suggesting a typical polygene mechanism. The Anoka $\times$ A7 population, however, demonstrated one QTL mapped on linkage group $\mathrm{N}$, contributing an average of $72.7 \%$ of the visual score variation and $68.8 \%$ of the chlorophyll concentration variation. Two other QTLs, one for the visual score and one for chlorophyll concentration, were detected on linkage groups A1 and I (chromosomes 5 and 20), respectively. This study supported previous reports by Cianzia and Fehr (1980, 1982) that IDC inheritance depends on the parents used in population development. The major QTL was located on an interval BLT15-Sat_033 of linkage group N. This region is near the aforementioned saline-tolerant QTL region. Studies with additional markers are required to elucidate the exact position of the QTL associated with IDC and its relationship with the saline-tolerant QTL.

Charlson et al. (2005) also tested the association of SSR markers with IDC in a population developed from a cross between Pioneer 9254 and A97-770012. The $F_{2}$ plants were genotyped with SSR markers, and the $\mathrm{F}_{2}$-derived lines $\left(\mathrm{F}_{2: 4}\right.$ and $\mathrm{F}_{2: 5}$ ) were evaluated for IDC resistance. Of the $108 \mathrm{SSR}$ markers tested, three were associated with IDC resistance: Satt211 (linkage group A1), Satt481 (linkage group L or chromosome 19) and Sat_104 (linkage group I); however, of the three markers, only Satt481 was associated with IDC resistance across environments. Although Satt481 accounted

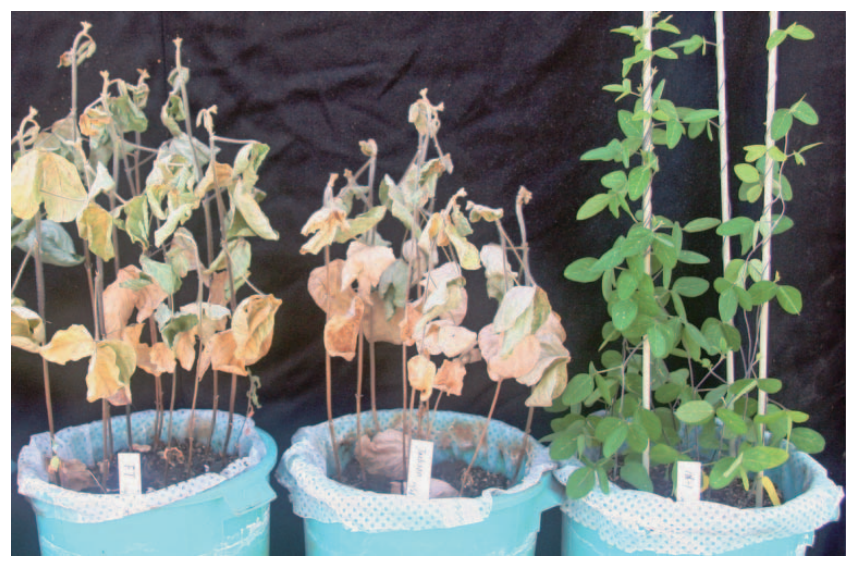

FT-Abyara (G. max) Jackson (G. max) JWS156-1 (G. soja)

Fig. 1. Comparison of sodic tolerance in the wild soybean accession (G. soja) JWS156-1 (right) and two cultivated soybean cultivars (G. max), Jackson (middle) and FT-Abyara (left), after sodic treatment with $180 \mathrm{mM} \mathrm{NaHCO}_{3}$ for approximately three weeks.

for only $12 \%$ of the total phenotypic variation, molecular analysis of the 11 most resistant lines in the population indicated that $73 \%$ of the lines were homozygous for the resistant allele at the Satt481 locus. These results indicated that Satt481 may be useful in improving IDC resistance in the soybean population and that additional QTLs conferring IDC resistance may exist in soybean. The QTL on linkage group $\mathrm{N}$ reported by Lin et al. (1997) was not detected by Charlson et al. (2005).

\section{Identification of a QTL allele for sodic tolerance from the} wild soybean accession JWS156-1

Tuyen et al. (2010) compared two wild soybean accessions for sodic tolerance with 55 soybean cultivars grown for approximately three weeks under greenhouse conditions using a salt-flooding evaluation method (180 $\left.\mathrm{mM} \mathrm{NaHCO}_{3}\right)$. They found that the wild soybean accession JWS156-1, which is tolerant to saline stress (Hamwieh and $\mathrm{Xu} 2008$ ), also had higher sodic tolerance than the 55 cultivated soybean cultivars. They used two populations, namely an $\mathrm{F}_{6}$ RIL mapping population $(n=112)$ and an $\mathrm{F}_{2}$ population $(n=149)$ derived from crosses between the soybean cultivar Jackson and JWS156-1, to identify the QTL for sodic tolerance. Soybean sodic tolerance was evaluated on the basis of the salt tolerance rating and leaf chlorophyll content after treatment with $180 \mathrm{mM} \mathrm{NaHCO}$ for approximately three weeks under greenhouse conditions. In both populations, a significant QTL for sodic tolerance was detected on molecular linkage group D2 (chromosome 17), which accounted for $50.2 \%$ and $13.0 \%$ of the total variation for sodic tolerance in the $F_{6}$ and $F_{2}$ populations, respectively. The wild soybean contributed the tolerance allele in the progeny. They concluded that the QTL for sodic tolerance differed from that for saline tolerance previously found in this wild soybean genotype; however, their results were based only on 
seedlings grown under greenhouse conditions. The QTL effect on sodic tolerance should be validated under actual sodic field conditions.

Hamwieh and $\mathrm{Xu}$ (2008) revealed that the wild soybean JWS156-1 was saline tolerant and that the tolerance QTL was located on linkage group N. Tuyen et al. (2010) found that JWS156-1 was also tolerant to sodic salt stress, with the tolerant QTL located on linkage group D2; therefore, it can be said that wild soybean JWS156-1 is tolerant to both saline and sodic stresses. FT-Abyara is also a saline-tolerant soybean cultivar (Hamwieh et al. 2011); however, it is not tolerant to sodic stress (Fig. 1). Therefore, saline tolerance may not always accompany sodic tolerance. However, MAS using DNA markers that are closely associated with the genes tolerant to different salt stresses could be utilized to develop soybean cultivars with high tolerances to saline and sodic soils.

\section{Conclusion and future perspective}

The above series of studies has clearly revealed that different genes condition saline and sodic tolerances in soybean. The DNA selection markers for MAS proposed by these studies can be used in a soybean breeding program for production areas threatened by saline and sodic stresses. Although significant efforts have been made to understand the inheritance of saline and sodic tolerances, more concentrated efforts are required from a breeding point of view to screen soybean germplasms, including those of wild soybean, to uncover new tolerant genes, and to pyramid the genes for higher levels of both saline and sodic tolerances.

As mentioned, knowledge of both saline and sodic stress tolerance mechanisms is still preliminary. With regard to saline tolerance, whether $\mathrm{Na}^{+}$or $\mathrm{Cl}^{-}$plays the most critical role in $\mathrm{NaCl}$-induced injury is still unknown. Regarding sodic tolerance, high soil $\mathrm{pH}$ directly affects plant growth. Indirectly, it affects plant growth by altering nutrient availability, which may result in nutrient deficiency or toxicity. For example, the availability of iron, manganese, and other micronutrients decreases with an increase in soil $\mathrm{pH}$. Identification and cloning of genes conferring saline and sodic tolerances will contribute a better understanding of saline and sodic stress tolerance mechanisms in soybean. Present studies on the identification of tolerant QTL, NIL development, target gene fine mapping, and availability of the entire soybean genome sequence (Schmutz et al. 2010) have provided significant resources for the positional cloning of saline and sodic tolerance genes. Cloning these tolerance genes would also facilitate the development of DNA selection markers and genetic engineering for soybean breeding to obtain higher levels of tolerance.

\section{Literature Cited}

Abel,G.H. (1969) Inheritance of the capacity for chloride inclusion and chloride exclusion by soybeans. Crop Sci. 9: 697-698.
Abel,G.H. and A.J.MacKenzie (1964) Salt tolerance of soybean varieties (Glycine max L. Merill) during germination and later growth. Crop Sci. 4: 157-161.

Alcántara,E., F.J.Romera and M.D.de la Guardia (1988) Genotypic differences in bicarbonate-induced iron chlorosis in sunflower. J. Plant Nutr. 11: 65-75.

Apse,M.P., G.S.Aharon, W.A.Snedden and E.Blumwald (1999) Salt tolerance conferred by overexpression of a vacuolar $\mathrm{Na}^{+} / \mathrm{H}^{+}$antiport in Arabidopsis. Science 285: 1256-1258.

Biatczyk,J., Z.Lechowski and A.Libik (1994) Growth of tomato seedlings under different $\mathrm{HCO}^{-}{ }_{3}$ concentration in the medium. J. Plant Nutr. 17: 801-816.

Celik,H. and A.VahapKatkat (2008) Effects of bicarbonate and iron deprivation on growth of different maize varieties. Am-Euras. J. Agric. \& Environ. Sci. 3: 169-178.

Chang,R.Z., Y.W.Chen, G.H.Shao and Z.W.Wan (1994) Effect of salt on agricultural characters and chemical quality of seed in soybean. Soybean Sci. 13: 101-105.

Charlson,D.V., T.B.Bailey, S.R.Cianzio and R.C.Shoemaker (2005) Molecular marker Satt481 is associated with iron-deficiency chlorosis resistance in a soybean breeding population. Crop Sci. 45: 2394-2399.

Chen,H.T., S.Y.Cui, S.X.Fu, J.Y.Gai and D.Y.Yu (2008) Identification of quantitative trait loci associated with salt tolerance during seedling growth in soybean (Glycine max L.). Aust. J. Agr. Res. 59: 1086-1091.

Cianzio,R.S. and W.R.Fehr (1980) Genetic control of iron deficiency chlorosis in soybeans. Iowa State J. Res. 54: 367-375.

Cianzio,R.S. and W.R.Fehr (1982) Variation in the inheritance of resistance to iron deficiency chlorosis in soybean. Crop Sci. 22: 433434.

Coulombe,B.A., R.L.Chaney and W.J.Wiebold (1984) Bicarbonate directly induces iron chlorosis in susceptible soybean cultivars. Soil Sci. Soc. Am. J. 48: 1297-1301.

FAO, AGL (2000) Extent and causes of salt affected soils in participating countries (http: //www.fao.org/ag/agl/agll/spush/topic2.htm).

Hamwieh,A. and D.H.Xu (2008) Conserved salt tolerance quantitative trait locus (QTL) in wild and cultivated soybeans. Breed. Sci. 58: 355-359.

Hamwieh,A., D.D.Tuyen, H.Cong, E.R.Benitez, R.Takahashi and D.H.Xu (2011) Identification of major QTL for salt tolerance in soybean. Euphytica 170: 451-459.

Hansen, N.C., M.A.Schmitt, J.E.Anderson and J.S.Strock (2003) Iron deficiency of soybean in the upper midwest and associated soil properties. Agron. J. 95: 1595-1601.

Lee, G.J., H.R.Boerma, M.R.Villagarcia, X.Zhou, T.E.Carter Jr, Z.Li and M.O.Gibbs (2004) A major QTL conditioning salt tolerance in S-100 soybean and descendent cultivars. Theor. Appl. Genet. 109: $1610-1619$.

Lee,J.D., G. Shannon, T.D.Vuong and H.T.Nguyen (2009) Inheritance of salt tolerance in wild soybean (Glycine soja Sieb. \& Zucc.) accession PI483463. J. Hered. 100: 798-801.

Lin, S., S.Cianzio and R. Shoemaker (1997) Mapping genetic loci for iron deficiency chlorosis in soybean. Mol. Breed. 3: 219-229.

Luo, Q.Y., B.J.Yu, Y.L.Liu, Y.M.Zhang, Y.L.Xue and Y.Zhang (2004) The mixed inheritance analysis of salt tolerance in cultivars of Glycine max. Soybean Sci. 23: 239-244.

Millar,A.L., A.J.Rathjen and D.S.Cooper (2007) Genetic variation for subsoil toxicities in high pH soils. In: Buck,H.T., J.E.Nisi and N.Salomön (eds.) Wheat Production in Stressed Environments, Springer, pp. 395-401. 
Norvell,W.A. and M.L.Adams (2006) Screening soybean cultivars for resistance to iron deficiency chlorosis in culture solutions containing magnesium or sodium bicarbonate. J. Plant Nutr. 29: 18551867.

Parker,M.B., G.J.Gascho and T.P.Gains (1983) Chloride toxicity of soybeans grown on Atlantic Coast flatwoods soils. Agron. J. 75: 439-443.

Quesada, V., S. García-Martínez, P. Piqueras, M.R. Ponce and J.L.Micol (2002) Genetic architecture of $\mathrm{NaCl}$ tolerance in Arabidopsis. Plant Physiol. 130: 951-963.

Ren,Z.H., J.P.Gao, L.G.Li, X.L.Cai, W.Huang, D.Y.Chao, M.Z.Zhu, Z.Y.Wang, S.Luan and H.X.Lin (2005) A rice quantitative trait locus for salt tolerance encodes a sodium transprter. Nat. Genet. 37: 1141-1146.

Rogovska,N.P., A.M.Blackmer and A.P.Mallarino (2007) Relationships between soybean yield, soil $\mathrm{pH}$, and soil carbonate concentration. Soil Sci. Soc. Am. J. 71: 1251-1256.

Schmutz, J., S.B.Cannon, J.Schlueter, J.Ma, T.Mitros, W.Nelson, D.L.Hyten, Q.Song, J.J.Thelen, J.Cheng et al. (2010) Genome sequence of the palaeopolyploid soybean. Nature 463: 178-183.

Shao,G.H., R.Z.Chang, Y.W.Chen and S.R.Yan (1994) Study on inheritance of salt tolerance in soybean. Acta Agronomica Sinica 20: 721-726.

Singleton,P.W. and B.B.Bohlool (1984) Effect of salinity on nodule formation by soybean. Plant Physiol. 74: 72-76.

Tuyen,D.D., S.K.Lal and D.H.Xu (2010) Identification of a major QTL allele from wild soybean (Glycine soja Sieb. \& Zucc.) for increasing alkaline salt tolerance in soybean. Theor. Appl. Genet.
121: 229-236.

Wang,D. and M.C.Shannon (1999) Emergence and seedling growth of soybean cultivars and maturity groups under salinity. Plant and Soil 214: 117-124.

Weiss, M.G. (1943) Inheritance and physiology of efficiency in iron utilization in soybean. Genetics 28: 253-268 (From Lin et al. 1997).

Xu,D.H. (2009) A simple method for evaluation of salt tolerance and its application on screening salt tolerance in wild soybean germplasm. Breed. Res. 11 (Suppl. 1): 241.

$\mathrm{Xu}, \mathrm{Y}$. and J.H.Crouch (2008) Marker-assisted selection in plant breeding: from publications to practice. Crop Sci. 48: 391-407.

Yamaguchi,T. and E.Blumwald (2005) Developing salt-tolerant crop plants: challenges and opportunities. Trends Plant Sci. 10: 615620 .

Yang,J. and R.W.Blanchar (1993) Differentinting chloride susceptibility in soybean cultivars. Agron. J. 85: 880-885.

Yang,X., V.Römheld and H.Marschner (1994) effect of bicarbonate on root growth and accumulation of organic acids in $\mathrm{Zn}$-ineffcient and Zn-efficient rice cultivars (Oryza sativar L.). Plant Soil 164: 1-7.

Zocchi,G, P.D.Nisi, M.Dell'Orto, L.Espen and P.M.Gallina (2007) Iron deficiency differently affects metabolic responses in soybean roots. J. Exp. Bot. 58: 993-1000.

Zuo, Y. and F.Zhang (2008) Effect of peanut mixed cropping with gramineous species on micronutrient concentrations and iron chlorosis of peanut plants grown in a calcareous soil. Plant Soil 306: 23-36. 